\title{
Symptoms in different severity degrees of bruxism: a cross-sectional study
}

Sintomas em diferentes graus de severidade de bruxismo: um estudo transversal

Los sintomas de diferentes niveles de gravedad del bruxismo: estudio transversal

Cinthia Santos Miotto Amorim', Glauco Fioranelli Vieira², Eliete Ferreira Osses Firsoff², Jecilene Rosana Costa Frutuoso ${ }^{3}$, Elizabeth Puliti ${ }^{2}$, Amélia Pasqual Marques ${ }^{1}$

\begin{abstract}
Objective: The aim of the present study was to evaluate symptoms of the muscle pain, sleep quality, oral health, anxiety, stress and depression in individuals with different severity degrees of bruxism. Methods: Seventytwo individuals with bruxism were enrolled in the study, classified into: moderate ( $n=25)$ and severe $(n=47)$ bruxism. Pain intensity was assessed using the Visual Analogical Scale, pain threshold with algometer, sleep quality by the Pittsburgh Sleep Quality Index, oral health by the Oral Health Impact Profile, anxiety by the State-Trait Anxiety Inventory, stress by the Perceived Stress Scale and depression using the Beck Depression Inventory. The significance level considered was 5\%. Results: The results showed that individuals with severe bruxism presented greater muscle pain intensity, sleep disorder, worse oral health, high anxiety level and dysphoria with statistically significant differences $(p<0.05)$ than individuals with moderate bruxism, except in pain threshold and stress $(p<0.05)$. Conclusion: Data suggest that individuals with severe bruxism have more intense symptoms. They present greater muscle pain, alterations in sleep quality and oral health, anxiety and depression than individuals with moderate bruxism. However, both present similarity in stress.
\end{abstract}

Keywords I Bruxism; Pain; Sleep; Oral Health; Anxiety.

RESUMO | Objetivo: Avaliar sintomas de dor muscular, qualidade de sono, saúde bucal, ansiedade, estresse e depressão em indivíduos com diferentes graus de severidade do bruxismo. Métodos: Setenta e dois indivíduos com bruxismo participaram do estudo e foram classificados com bruxismo moderado ( $n=25)$ e severo ( $n=47)$. A intensidade da dor foi avaliada pela Escala Visual Analógica, limiar de dor com o algômetro, qualidade de sono pelo Índice de Qualidade de Sono de Pittsburgh, saúde bucal pelo Perfil de Impacto de Saúde Bucal, ansiedade pelo Inventário de Ansiedade TraçoEstado, estresse pela Escala de Estresse Percebido e depressão pelo Inventário de Depressão de Beck. O nível de significância considerado foi 5\%. Resultados: Os resultados demonstraram que indivíduos com bruxismo severo apresentaram maior intensidade de dor muscular, distúrbio do sono, pior qualidade de saúde bucal, elevado grau de ansiedade e disforia, com diferenças estatisticamente significantes $(p<0,05)$ comparados com bruxismo moderado, exceto no limiar de dor e estresse ( $p>0,05)$. Conclusão: Os dados sugerem que indivíduos com bruxismo severo tem sintomas mais intensos. Eles apresentam maior intensidade de dor muscular, alterações na qualidade do sono e saúde bucal, ansiedade e depressão do que indivíduos com bruxismo moderado. Porém, ambos apresentam similaridade no estresse.

Palavras-chave | Bruxismo; Dor; Sono; Saúde Bucal; Ansiedade.

RESUMEN | Objetivo: Evaluar los síntomas dolor muscular, calidad de sueño, salud bucal, ansiedad, estrés y depresión en sujetos con diferentes niveles de gravedad del bruxismo. Método: Participaron del estudio 72 personas con bruxismo, clasificado según los niveles moderado $(n=25)$ y grave $(\mathrm{n}=47)$. Se evaluaron la intensidad del dolor mediante la

'Department of Physical Therapy, Speech-language Pathology and Audiology and Occupational Therapy, School of Medicine, University of São Paulo São Paulo (SP), Brazil.

2Department of Operative Dentistry, School of Dentistry, University of São Paulo São Paulo (SP), Brazil.

${ }^{3}$ Department of Pediatric Otolaryngology, Federal University of São Paulo São Paulo (SP), Brazil. 
Escala Visual Analógica, umbral de dolor con algómetro, la calidad de sueño por el Índice de Calidad de Sueño de Pittsburgh, la salud bucal mediante el Perfil del Impacto de Salud Bucal, la ansiedad por el Inventario de Ansiedad Rasgo-Estado, el estrés mediante la Escala de Estrés Percibido y la depresión por el Inventario de Depresión de Beck. Se consideró el nivel de significación de 5\%. Resultados: Los sujetos con bruxismo grave presentaron más intensamente dolor muscular, trastorno de sueño, peor calidad de salud bucal, alto grado de ansiedad y disforia, con diferencias estadísticamente significativas $(p<0,05)$ en comparación con los sujetos con bruxismo moderado, con excepción del umbral de dolor y estrés $(p>0,05)$. Conclusión: Los datos mostraron que los sujetos con bruxismo grave sufren síntomas más intensos. A pesar de sufrir síntomas más intensos de dolor muscular, calidad de sueño y salud bucal alterada, ansiedad y depresión que los sujetos con bruxismo moderado, el estrés está presente en los dos niveles de bruxismo.

Palabras clave | Bruxismo; Dolor; Sueño; Salud Bucal; Ansiedad.

\section{INTRODUCTION}

A recent international consensus defined bruxism as a repetitive jaw-muscle activity characterized by the clenching and/or grinding of the teeth and/or by the bracing or thrusting of the mandible, which can occur during the day and/or while sleeping ${ }^{1}$. In addition, bruxism can be classified as primary, which is not related to clinical disorders; or secondary, associated with other conditions $^{2}$. Although the prevalence of sleep and awake bruxism in adults is approximately $8 \%$ and $20 \%$, respectively, studies have indicated that between $85 \%$ and $90 \%$ of the population have possibly succumbed to episodes of bruxism throughout their lives ${ }^{3}$.

Bruxism can be associated with different factors such as peripheral (morphological), pathophysiological (central) and psychosocial factors ${ }^{2}$. Psychosocial factors, such as anxiety, stress and depression, can trigger and perpetuate bruxism ${ }^{4}$. Consequently, bruxism can cause masticatory and cervical muscle pain; headache; decrease pain thresholds in the orofacial and cervical muscles; change sleep quality and oral health; and increase anxiety, stress and depression ${ }^{2,4}$.

Persistent stressful situations can be associated with the increasing and significant seek for treatments for bruxism and its symptoms in recent years ${ }^{5,6}$. In this regard, bruxism affects millions of people throughout the world and is considered the most detrimental among all the parafunctional activities of the stomatognathic system $^{4}$. Even though some support for the association among bruxism, pain, change in sleep quality and oral health; anxiety, stress and depression has been provided, it remains a controversial issue. While bruxism can trigger these symptoms, it can also be generated by them ${ }^{2,4,7-16}$. Although there are studies about bruxism and psychosocial symptoms, those that associate bruxism with muscle pain, sleep quality, oral health, anxiety, stress and depression simultaneously are scarce, methodologically different and poor. In addition, some of these studies present lack of information about bruxism type, heterogeneous assessment tools and the use of single clinical approach to the diagnosis of bruxism, not allowing a distinction between the sleep and awake bruxism ${ }^{2,4,7-16}$.

Therefore, the knowledge of symptoms in different severity degrees of the bruxism is relevant for choice of therapeutic approaches, such as physiotherapeutic interventions and dental treatments, with the objectives of preventing and/or controlling bruxism and its symptoms ${ }^{5,6}$. Thus, the objective of this study was to evaluate symptoms of the muscle pain, sleep quality, oral health, anxiety, stress and depression in individuals with different severity degrees of bruxism.

\section{METHODOLOGY}

This study included 72 individuals with bruxism aged 18-60 years from a school of dentistry.

Participants were classified into: moderate bruxism $(n=25)$ and severe bruxism $(n=47)$. We used the bruxism severity classification questionnaire that consists of 25 items: mild (3-5 points), moderate (6-10 points) or severe (11-15 points). These points are based on several signs and symptoms of bruxism ${ }^{6,17}$. Figure 1 shows the flow diagram of the study.

Sleep and awake bruxism diagnoses were based on clinical examination and anamnesis by the professional dentist of sleep and awake bruxism, confirmed by the diagnostic criteria of International Classification for Sleep Disorders (ICSD) of the American Academy of Sleep Medicine ${ }^{18}$, and positive response to the question based on the recommendations of Pintado"19: "Were 
you or are you aware of clenching and/or grinding your teeth during the day?", respectively.

Participants with more than two missing teeth, except the third molars; systemic and/or degenerative disease; neurological and/or psychiatric disorders (except anxiety and depression) by doctor; use of medication that could affect the sleep or motor behavior; periodontal diseases and direct trauma or past surgical in the orofacial region were excluded.

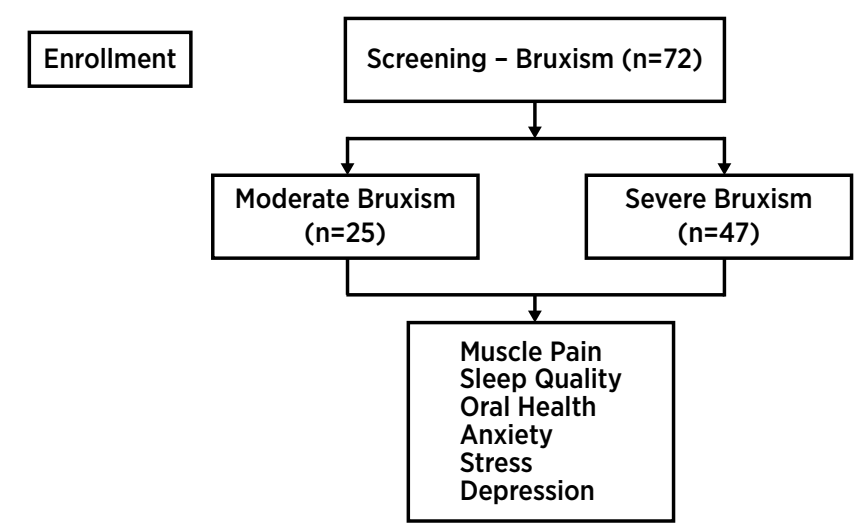

Figure 1. Flow diagram of the study

\section{Procedures}

Demographic and anthropometric data were collected, as well as the bruxism history. For the degree of severity of the parafunctional habits, we used severity classification questionnaire that consists of 14 items: mild (3-5 points), moderate (6-10 points) or severe (1114 points) ${ }^{20}$; pattern of cervical spine curvature (normal, hyperlordosis or rectification) was determined by radiograph; and maximum active mouth opening using a digital pachimeter (Digimess ${ }^{\circledR}, \mathrm{www}$.digimess.com.br, São Paulo, Brazil). Pain, sleep quality, oral health, anxiety, stress and depression outcomes were also assessed ${ }^{21 .}$

\section{Pain}

Severity of pain of the masseter, anterior temporalis, upper trapezius and sternocleidomastoid muscles separately, at rest at the moment of evaluation, was assessed using the Visual Analogical Scale (VAS), constructed as a $10 \mathrm{~cm}$ horizontal line. The labels "no pain"(left) and "worst imaginable pain" (right) were used. Participants were instructed to mark pain intensity ${ }^{21}$.

Pain threshold was evaluated using an algometer (Fischer, www.wagnerinstruments.com, Greenwich, $\mathrm{CT}$ ) with a rubber extremity with $1 \mathrm{~cm}$ of diameter.
Perpendicular pressure was applied on the trigger points of the masseter superficial fibers, anterior temporalis, upper trapezius, and sternocleidomastoid sternal division muscles, bilaterally and increased at a rate of approximately $1 \mathrm{~kg} / \mathrm{s}$. Pain threshold of trigger points of most tender were reported by participants upon digital pressure stimulation by a trained single examiner, marked with demographic pencil and considered positive when values were lower than $2.6 \mathrm{~kg} / \mathrm{cm}^{2}$ according to Marques et $\mathrm{al}^{22}$. Pain threshold reflects the lowest intensity of pressure at which an individual perceives pain ${ }^{22}$.

Severity of symptoms: teeth clenching, sleeping difficulty and primary tension type headache were assessed using Visual Analogical Scales (VAS) at the time of the assessment. For teeth clenching, the labels "absence" (left) and "maximum clenching" (right) were used; for sleep difficulty, "no difficulty" and "very difficult"; and for headache, "no headache" and "worst imaginable headache". Participants were instructed to mark the intensity of symptoms ${ }^{21}$.

\section{Sleep quality}

Sleep quality during the last month was measured using the Pittsburgh Sleep Quality Index (PSQI) ${ }^{23}$. This questionnaire has been translated and validated into Portuguese. It consists of 19 questions grouped into seven domains. Total score range from 0 to 4: good sleep quality; 5 to 10: poor sleep quality; or above 10: sleep disorder ${ }^{24}$.

\section{Oral health}

The assessment of oral health was performed by using the Oral Health Impact Profile -14 (OHIP-14). This questionnaire has been translated and validated into Portuguese. It consists of 14 questions. Total scores range from 0 to 56 , and higher scores are suggestive of poor oral health ${ }^{25,26}$.

\section{Anxiety}

Anxiety was assessed using the State-Trait Anxiety Inventory (STAI), which has been translated and validated to the Portuguese language. It consists of two independent scales, with 20 questions each, measuring anxiety as a trait (in general) and as a state (at the moment). Total scores for the scales range from 20 to 80 as follows: low anxiety (20 to 34$)$; moderate anxiety ( 35 to 49 ); high anxiety (50 to 64$)$; and very high anxiety (65 to 80$)^{27,28}$. 


\section{Stress}

Stress was evaluated using the Perceived Stress Scale (PSS-10), which has also been translated and validated to Portuguese. It consists of 10 questions with scores ranging from 0 to 4 . Total scores range from 0 to 40 , and higher values suggest higher stress levels ${ }^{29,30}$.

\section{Depression}

The Beck Depression Inventory (BDI) was used to assess depression. It has also been translated and validated to Portuguese and consists of 21 groups of four statements, assessing depressive symptoms over the last week. Scores below or similar to 15 suggest normality; from 16 to 20, dysphoria; and from 21 to 63 , the individuals are deemed as having indications of depression, even if without a diagnostic of the disease ${ }^{31,32}$.

\section{Statistical analysis}

Descriptive statistics included mean and standard deviation or median and percentiles and percentage of gender, marital status, education, parafunctional habits and pattern of cervical curvature. Normality of data distribution was tested using the KolmogorovSmirnov test. Student t-test was used for parametric outcomes and the Mann-Whitney test for nonparametric outcomes for the analyses between the two groups (moderate bruxism and severe bruxism). All data were analyzed using the SigmaStat 3.5 and SPSS 19 software. A level of significance of $\alpha=5 \%$ was used.

\section{RESULTS}

Data regarding the clinical and demographic characteristics are presented in Table 1. Individuals with moderate and severe bruxism were similar for the variables: age, mass, height, body mass index (BMI) and mouth opening.

Table 2 describes data of pain in the masseter, anterior temporal, sternocleidomastoid and upper trapezius muscles; pain threshold; teeth clenching; sleeping difficulty; tension type headache; sleep quality, oral health, anxiety, stress and depression of the individuals with moderate and severe bruxism. The data showed statistically significant differences for all the variables $(p<0.05)$, except for pain threshold and stress $(p>0.05)$.

Table 1. Demographic and clinical characteristics of individuals with bruxism

\begin{tabular}{|c|c|c|c|c|}
\hline Outcomes & $\begin{array}{c}\text { Bruxism M }(n=25) \\
\text { Mean (SD) }\end{array}$ & $\begin{array}{c}\text { Bruxism S }(n=47) \\
\text { Mean }(S D)\end{array}$ & $\begin{array}{l}\text { Total }(n=72) \\
\text { Mean (SD) }\end{array}$ & $p^{*}$ \\
\hline Age (years) & $35(9.8)$ & $38(11.5)$ & $37(10.7)$ & 0.185 \\
\hline Mass (kg) & $68(12.7)$ & 69.8 (13.9) & $68.9(13.3)$ & 0.683 \\
\hline Height (cm) & $1.7(0.1)$ & $1.7(0.1)$ & $1.7(0.1)$ & 0.783 \\
\hline $\mathrm{BMI}\left(\mathrm{kg} / \mathrm{cm}^{2}\right)$ & $24(4.3)$ & $25(4.5)$ & $25(4.4)$ & 0.182 \\
\hline \multirow[t]{2}{*}{ Mouth opening $(\mathrm{cm})$} & $4.8(7.5)$ & $4.7(7.3)$ & $4.8(7.4)$ & 0.483 \\
\hline & $n(\%)$ & $n(\%)$ & $n(\%)$ & \\
\hline \multicolumn{5}{|l|}{ Gender } \\
\hline Female & $16(64)$ & $35(74)$ & $51(71)$ & \\
\hline \multicolumn{5}{|l|}{ Marital status } \\
\hline Single & $16(64)$ & $20(43)$ & $36(50)$ & \\
\hline Married & $7(28)$ & $22(47)$ & $29(40)$ & \\
\hline Divorced & $2(8)$ & $5(11)$ & $7(10)$ & \\
\hline \multicolumn{5}{|l|}{ Education (years) } \\
\hline 9 to 12 & $8(32)$ & $20(43)$ & $28(39)$ & \\
\hline More than 12 & $17(68)$ & $27(57)$ & $44(61)$ & \\
\hline \multicolumn{5}{|l|}{ Parafuncional Habits } \\
\hline Mild (3-5) & $16(64)$ & $27(57)$ & $43(60)$ & \\
\hline Moderate (6-10) & $9(36)$ & $20(43)$ & $29(40)$ & \\
\hline \multicolumn{5}{|l|}{ Cervical Curvature } \\
\hline Normal & $7(28)$ & $11(23)$ & $18(25)$ & \\
\hline Hyperlordosis & $6(24)$ & $13(28)$ & $19(26)$ & \\
\hline Rectification & $12(48)$ & $23(49)$ & $35(49)$ & \\
\hline
\end{tabular}

* p values: t-test between Bruxism M (moderate) and Bruxism S (severe). BMI: Body Mass Index. 
Table 2. Muscle pain, sleep quality, oral health, anxiety, stress and depression in individuals with bruxism

\begin{tabular}{|c|c|c|c|}
\hline \multirow{3}{*}{ Outcomes } & Bruxism M $(n=25)$ & Bruxism S ( $n=47)$ & \multirow{3}{*}{$\mathbf{p}$} \\
\hline & Mean (SD) & Mean (SD) & \\
\hline & Median [25-75\%] & Median [25-75\%] & \\
\hline \multicolumn{4}{|l|}{ Muscle Pain $(0-10 \mathrm{~cm})$} \\
\hline Masseter & $4.9[3-7]$ & $7.3[6-8]$ & $<0.001^{*}$ \\
\hline Anterior Temporal & $5.6(2.4)$ & $6.9(2.1)$ & $0.025^{*}$ \\
\hline Sternocleidomastoid & $5.5(1.8)$ & $6.6(2.2)$ & $0.035^{*}$ \\
\hline Upper Trapezius & $6.4(2.1)$ & $7.8(1.8)$ & $0.005^{*}$ \\
\hline \multicolumn{4}{|l|}{ Pain threshold $\left(\mathrm{kg} / \mathrm{cm}^{2}\right)$} \\
\hline Masseter R & $1.1(0.4)$ & $1.1(0.4)$ & 0.814 \\
\hline Masseter L & $1.1(0.4)$ & $1.1(0.4)$ & 0.910 \\
\hline Anterior Temporal R & $1.3(0.4)$ & $1.3(0.5)$ & 0.859 \\
\hline Anterior Temporal L & $1.3(0.4)$ & $1.2(0.4)$ & 0.275 \\
\hline Sternocleidomastoid R & $1.4(0.5)$ & $1.4(0.5)$ & 0.845 \\
\hline Sternocleidomastoid L & $1.1(0.4)$ & $1.1(0.3)$ & 0.550 \\
\hline Superior Trapezius R & $1.9(0.9)$ & $1.7(0.6)$ & 0.228 \\
\hline Superior Trapezius L & $1.3(0.3)$ & $1.4(0.4)$ & 0.310 \\
\hline Teeth Clenching (0-10cm) & $8.2[6-9]$ & $9[8-10]$ & $0.016^{*}$ \\
\hline Sleeping Difficulty (0-10cm) & $4.4(2.4)$ & $6.9(2.8)$ & $<0.001^{*}$ \\
\hline Tension Type Headache $(0-10 \mathrm{~cm})$ & $6(2.9)$ & $7.5(2.3)$ & $0.029 *$ \\
\hline Sleep quality $(0-21)$ & $9[8-10]$ & 12 [10-13] & $<0.001^{*}$ \\
\hline Oral health (0-56) & $17(7.2)$ & $26(7.8)$ & $<0.001^{*}$ \\
\hline \multicolumn{4}{|l|}{ Anxiety (20-80) } \\
\hline State & 49 (11) & $55(8.2)$ & $0.028^{*}$ \\
\hline Trait & $46(10.8)$ & $52(10.2)$ & $0.035^{*}$ \\
\hline Stress $(0-40)$ & $22(5.2)$ & $23(5.3)$ & 0.453 \\
\hline Depression (0-63) & $13(5.6)$ & $18(5.6)$ & $0.002^{*}$ \\
\hline
\end{tabular}

* $p$ values: t-test between Bruxism M (moderate) and Bruxism S (severe). R: right, L: left

\section{DISCUSSION}

Results demonstrated that individuals with severe bruxism had more muscle pain, alterations in sleep quality and oral health, anxiety and dysphoria than individuals with moderate bruxism. However, both presented similarity in pain threshold and stress. Greater intensities of muscle pain were observed in individuals with severe bruxism, although both groups presented low or positive values of pain threshold in the trigger points of most tender ${ }^{22}$.

Therefore, pain occurs not only in masticatory muscles, but also in the craniofacial complex and cervical spine, characterized by pain originating in trigger points located in palpable nodules in the tense fiber band of the masticatory muscles, whose participation in the toning activity of the cervical muscles is also evident ${ }^{13}$. In parallel, low orofacial and cervical muscle pain thresholds due to bruxism reflect increase in nociceptive excitability at these specific points ${ }^{7,33}$.
In our study, individuals with headache reported greater intensity of teeth clenching and pain, and studies shown that $65 \%$ of individuals with bruxism have temporal tensional type headaches, probably due to tonic muscle hyperactivity of the masticatory muscles ${ }^{8,34}$. A study demonstrated association between sleep bruxism and tensional type headaches, indicating that individuals with bruxism have a three-fold higher chance of developing them, justified by the central sensitization mechanism released by trigger points present in the craniofacial muscles ${ }^{13,35}$.

In addition to moderate sleeping difficulty, individuals with severe bruxism presented sleep disorder. In contrast, individuals with moderate bruxism demonstrated mild sleeping difficulty and poor sleep quality. This indicates a negative association between sleep quality and bruxism, which constitutes a sleep-related movement disorder defined as oral activity characterized by grinding or clenching of the teeth during sleep, associated with sleep arousals ${ }^{1}$, excessive diurnal tiredness, insufficient and non-recuperative sleep and insomnia with sleep 
interruptions. Another study associated less than eight hours sleep, alteration in subjective quality, disturbances and habitual efficiency with sleep and awake bruxism, suggesting compromising of good sleep quality, everyday activities and exacerbation of psychosocial factors, which can contribute to increase bruxism ${ }^{2,10}$.

The more severe the bruxism, probably the greater is the negative self-perception of the social impact and oral health-related quality of life, corresponding to $46 \%$ of the individuals with severe bruxism compared with $37 \%$ of individuals with moderate bruxism in this study. This suggests that bruxism is potentially detrimental to oral health due to the unpleasant effects such as destroying teeth and breaking fillings ${ }^{10}$.

In recent years, there has been an increase in the attention focused on oral health, since it is considered to be an important aspect of disorders as bruxism, due to the resulting symptoms such as physical pain, present in the individuals who enrolled in our study ${ }^{11,25}$.

Psychosocial factors are associated with bruxism and some studies have indicated that anxiety is one of the most altered. The more severe the bruxism, the higher is the trait and state anxiety, indicating a difference between individuals with moderate and severe bruxism, as observed in our study ${ }^{15,30}$.

It appears that children with bruxism are more anxious than children without bruxism, and chances of an anxious child developing bruxism range from 36\% to $40 \%{ }^{36}$. Similarly, it seems that individuals with more severe bruxism tend to show a moderate to severe level of anxiety, different from those without bruxism or with the mild form ${ }^{37}$.

Both individuals with moderate and severe bruxism in this study had stress perception of about $60 \%$, corroborating evident and association of stress with moderate to severe bruxism due to the increase in the level of catecholamine (stress hormones) in the urine $\mathrm{e}^{14}$. It appears that stress determines the occurrence of bruxism, and both contribute to the origin and maintenance of pain, a marked characteristic in our study ${ }^{34,38}$.

Individuals with moderate and severe bruxism presented normality and dysphoria, respectively; similar to the study that indicated an association of pain and depression ${ }^{39}$. It has also been suggested that bruxism and pain probably increase the risk of moderate to severe depression, pointing out that pain is maintained by constant peripheral muscle sensitization impulses, increasing the levels of depression and other symptoms ${ }^{12}$. In addition, indicatives of depression are common in bruxism, since the risk of developing it is greater, although the role of the neurotransmitters of the central nervous system, such as dopamine, is still not completely clear ${ }^{4}$.

Numerous consequences of bruxism are not limited to dental problems and stomatognathic system. As observed in this study, the more severe the bruxism, probably the greater may be muscle pain, alterations in sleep and oral health quality, anxiety and dysphoria, which can be associated with the increasing and significant number of seek for treatment for bruxism. It indicates the need for health services focused on differentiated therapeutic approaches, such as physiotherapeutic interventions and dental treatments, aiming at preventing and/ or controlling bruxism and its symptoms. According to other study, symptoms of bruxism are the best and preferable variables for the evaluation of individuals with bruxism, suggesting that bruxism treatment should be performed by a multidisciplinary team involving a combination of therapeutic resources aiming to achieve positive results in reduction in symptoms ${ }^{5,6}$.

Although bruxism can occur during both wakefulness and sleep, the majority of studies do not distinguish between these forms of bruxism. It is usually grouped together and generically referred to as "bruxism". In our study, a distinction was performed by the professional dentist based on clinical examination and anamnesis confirmed by the two different tools: one for awake bruxism and another for sleep bruxism. Moreover, they are the easiest and most adopted acceptable methods to gather data in large-sample studies ${ }^{4}$.

\section{CONCLUSION}

Data suggest that individuals with severe bruxism have more intense symptoms. They present greater muscle pain, alterations in sleep quality and oral health, anxiety and depression than individuals with moderate bruxism. However, both present similarity in stress.

\section{REFERENCES}

1. Lobbezoo F, Ahlberg J, Glaros AG, Kato T, Koyano K, Lavigne GJ, et al. Bruxism defined and graded: an international consensus. J Oral Rehabil. 2013;40(1):2-4.

2. Shetty S, Pitti V, Satish Babu CL, Surendra Kumar GP, Deepthi BC. Bruxism: a literature review. J Indian Prosthodont Soc. 2010;10(3):141-8. 
3. Koyano K, Tsukiyama Y, Ichiki R, Kuwata T. Assessment of bruxism in the clinic. J Oral Rehabil. 2008;35(7):495-508.

4. Manfredini D, Lobbezoo F. Role of psychosocial factors in the etiology of bruxism. J Orofac Pain. 2009;23(2):153-66.

5. Wieckiewicz M, Paradowska-Stolarz A, Wieckiewicz W. Psychosocial aspects of bruxism: the most paramount factor influencing teeth grinding. Biomed Res Int. 2014;2014:469187.

6. Molina OF, dos Santos Junior J, Nelson SJ, T. N. Profile of TMD and Bruxer compared to TMD and nonbruxer patients regarding chief complaint, previous consultations, modes of therapy, and chronicity. Cranio: the journal of craniomandibular practice. 2000;18:205-19.

7. Rajpurohit B, Khatri SM, Metgud D, Bagewadi A. Effectiveness of transcutaneous electrical nerve stimulation and microcurrent electrical nerve stimulation in bruxism associated with masticatory muscle pain--a comparative study. Indian J Dent Res. 2010 Jan-Mar;21(1):104-6.

8. Serra-Negra JM, Paiva SM, Auad SM, Ramos-Jorge ML, Pordeus IA. Signs, symptoms, parafunctions and associated factors of parent-reported sleep bruxism in children: a casecontrol study. Braz Dent J. 2012;23(6):746-52.

9. Serra-Negra JM, Paiva SM, Flores-Mendoza CE, Ramos-Jorge ML, Pordeus IA. Association among stress, personality traits, and sleep bruxism in children. Pediatr Dent. 2012;34(2):e30-4.

10. Serra-Negra JM, Scarpelli AC, Tirsa-Costa D, Guimaraes FH, Pordeus IA, Paiva SM. Sleep bruxism, awake bruxism and sleep quality among Brazilian dental students: a crosssectional study. Braz Dent J. 2014;25(3):241-7.

11. Dahlstrom L, Carlsson GE. Temporomandibular disorders and oral health-related quality of life. A systematic review. Acta Odontol Scand. 2010;68(2):80-5.

12. Fernandes G, Franco AL, Siqueira JT, Goncalves DA, Camparis CM. Sleep bruxism increases the risk for painful temporomandibular disorder, depression and non-specific physical symptoms. J Oral Rehabil. 2012;39(7):538-44.

13. Fernandez-de-Las-Penas C, Ge HY, Arendt-Nielsen L, Cuadrado ML, Pareja JA. The local and referred pain from myofascial trigger points in the temporalis muscle contributes to pain profile in chronic tension-type headache. Clin J Pain. 2007;23(9):786-92.

14. Ommerborn MA, Schneider C, Giraki M, Schafer R, Handschel J, Franz M, et al. Effects of an occlusal splint compared with cognitive-behavioral treatment on sleep bruxism activity. Eur J Oral Sci. 2007;115(1):7-14.

15. Winocur E, Uziel N, Lisha T, Goldsmith C, Eli I. Self-reported bruxism - associations with perceived stress, motivation for control, dental anxiety and gagging. J Oral Rehabil. 2011;38(1):3-11.

16. Manfredini D, Lobbezoo F. Relationship between bruxism and temporomandibular disorders: a systematic review of literature from 1998 to 2008. Oral Surg Oral Med Oral Pathol Oral Radiol Endod. 2010;109(6):e26-50.

17. Molina OF, Simião BRH, Marchezan RF, Silva NDP, KR. G. A comprehensive method to classify subgroups of bruxers in temporomandibular disorders (TMDs) individuals: frequency, clinical and psychological implications. RSBO. 2013;10:11-9.
18. Sateia MJ. International classification of sleep disordersthird edition: highlights and modifications. Chest. 2014;146(5):1387-94.

19. Pintado MR, Anderson GC, DeLong R, Douglas WH. Variation in tooth wear in young adults over a two-year period. J Prosthet Dent. 1997;77(3):313-20.

20. Molina OF, dos Santos J, Mazzetto M, Nelson S, Nowlin T, Mainieri ET. Oral jaw behaviors in TMD and bruxism: a comparison study by severity of bruxism. Cranio. 2001;19(2):114-22.

21. Maluf SA, Moreno BG, Crivello O, Cabral CM, Bortolotti G, Marques AP. Global postural reeducation and static stretching exercises in the treatment of myogenic temporomandibular disorders: a randomized study. J Manipulative Physiol Ther. 2010;33(7):500-7.

22. Marques AP, Ferreira EA, Matsutani LA, Pereira CA, Assumpcao A. Quantifying pain threshold and quality of life of fibromyalgia patients. Clin Rheumatol. 2005;24(3):266-71.

23. Bertolazi AN, Fagondes SC, Hoff LS, Dartora EG, Miozzo IC, de Barba ME, et al. Validation of the Brazilian Portuguese version of the Pittsburgh Sleep Quality Index. Sleep Med. 2011;12(1):70-5.

24. Buysse DJ, Reynolds CF, 3rd, Monk TH, Berman SR, Kupfer DJ. The Pittsburgh Sleep Quality Index: a new instrument for psychiatric practice and research. Psychiatry Res. 1989;28(2):193-213.

25. Oliveira BH, Nadanovsky P. Psychometric properties of the Brazilian version of the Oral Health Impact Profile-short form. Community Dent Oral Epidemiol. 2005;33(4):307-14.

26. Slade GD. Derivation and validation of a short-form oral health impact profile. Community Dent Oral Epidemiol. 1997;25(4):284-90

27. Spielberger CD. Manual for the State-Trait Anxiety Inventory (STAl: Form Y). Palo Alto, CA: Consulting Psychologists; 1983.

28. Biaggio AMB. Tradução e Adaptação do Manual de Psicologia Aplicada IDATE. Rio de Janeiro1979.

29. Cohen S, Kamarck T, Mermelstein R. A global measure of perceived stress. J Health Soc Behav. 1983;24(4):385-96.

30. Reis RS, Hino AA, Anez CR. Perceived stress scale: reliability and validity study in Brazil. J Health Psychol. 2010;15(1):107-14.

31. Gorenstein C, Andrade, L. Validation of a Portuguese version of the Beck Depression Inventory and the State-Trait Anxiety Inventory in Brazilian subjects. Braz J Med Biol Res. 1996;29(4):453-7.

32. Beck AT, Ward CH, Mendelson M, Mock J, Erbaugh J. An inventory for measuring depression. Arch Gen Psychiatry. 1961;4:561-71

33. Conti PC, Stuginski-Barbosa J, Bonjardim LR, Soares S, Svensson P. Contingent electrical stimulation inhibits jaw muscle activity during sleep but not pain intensity or masticatory muscle pressure pain threshold in self-reported bruxers: a pilot study. Oral Surg Oral Med Oral Pathol Oral Radiol. 2014 Jan;117(1):45-52.

34. Carra MC, Huynh N, Morton P, Rompre PH, Papadakis A, Remise C, et al. Prevalence and risk factors of sleep bruxism and wake-time tooth clenching in a 7- to 17-yr-old population. Eur J Oral Sci. 2011;119(5):386-94. 
35. De Luca Canto G, Singh V, Bigal ME, Major PW, Flores-Mir C. Association between tension-type headache and migraine with sleep bruxism: asystematic review. Headache. 2014;54(9):1460-9.

36. Restrepo CC, Alvarez E, Jaramillo C, Velez C, Valencia I. Effects of psychological techniques on bruxism in children with primary teeth. J Oral Rehabil. 2001 ;28(4):354-60.

37. Ahlberg J, Lobbezoo F, Ahlberg K, Manfredini D, Hublin C, Sinisalo J, et al. Self-reported bruxism mirrors anxiety and stress in adults. Med Oral Patol Oral Cir Bucal. 2013;18(1):e7-11.
38. Ahlberg K, Savolainen A, Paju S, Hublin C, Partinen M, Kononen $M$, et al. Bruxism and sleep efficiency measured at home with wireless devices. J Oral Rehabil. 2008;35(8):567-71.

39. Castro-Sanchez AM, Mataran-Penarrocha GA, GraneroMolina J, Aguilera-Manrique G, Quesada-Rubio JM, MorenoLorenzo C. Benefits of massage-myofascial release therapy on pain, anxiety, quality of sleep, depression, and quality of life in patients with fibromyalgia. Evid Based Complement Alternat Med. 2011;2011:561753. 